\title{
Adeus à divisão sexual do trabalho? Desigualdade de gênero na cadeia produtiva da confecção
}

Reginaldo Guiraldelli ${ }^{1}$

Resumo: A divisão sexual do trabalho, no marco da reestruturação produtiva, que desencadeou processos de terceirização, informalidade e subcontratações, é um assunto que ainda requer estudos e pesquisas com vistas a decifrar elementos presentes na esfera produtiva que reforçam as desigualdades de gênero no mundo do trabalho. Por isso, este artigo objetiva apresentar alguns aspectos desse fenômeno complexo, suscitando reflexões acerca de um suposto fim da divisão sexual do trabalho, diante de discursos disseminados que atestam para a igualdade entre homens e mulheres na esfera produtiva. Essa concepção é questionável considerando que ainda se sustentam determinadas ocupações no mundo do trabalho como redutos femininos por excelência, como é o caso da indústria da confecção.

Palavras-chave: Trabalho, Gênero, Precarização, Confecção, Questão Social.

\section{Questões introdutórias}

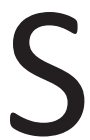

ão recorrentes as literaturas que consideram a incorporação do trabalho feminino de forma mais expressiva no findar do século XVIII e início do século XIX, fase que marca a consolidação capitalista, quando as mulheres foram absorvidas pelas indústrias para exercerem inúmeras atividades, com destaque para o ramo têxtil. A partir desse recorte temporal, as mulheres ocuparam espaços no mundo do trabalho e passaram a se submeter a extensas jornadas e condições de trabalho degradantes, tendo como principais ocupações o serviço doméstico, o emprego agrícola, domiciliar e fabril, com destaque para a costura.

No Brasil, já no início do século XX, considerando a divisão sexual do trabalho, as mulheres ocupavam postos nas indústrias, com destaque para alguns setores como: fiação, tecelagem, calçado, vestuário e alimentação, com uma presença predominante nas atividades da costura, conforme observado nos estudos de Abreu (1986).

Adotar o trabalho feminino em alguns ramos industriais era conveniente, em decorrência da concepção de serem as mulheres mais dóceis, pacientes,
Recebido:

17.10.2011

Aprovado:

24.09.2012

1. Professor Adjunto do Departamento de Serviço Social da Universidade de Brasília (UnB) E-mail: reginaldog@unb.br 
menos reivindicativas, além do pagamento de salários inferiores, por significar um rendimento complementar ao orçamento familiar. Diante das necessidades produtivas e do impulso industrial brasileiro, no início do século XX, o segmento feminino passou a incorporar o conjunto de trabalhadores/as fabris e urbanos, mas durante várias décadas,

(...) o campo de atuação da mulher fora do lar circunscreveuse ao de ajudante, assistente, ou seja, a uma função de subordinação a um chefe masculino em atividades que as colocaram desde sempre à margem de qualquer processo decisório. No caso da operária, mesmo num ramo onde sua participação era enorme, como o têxtil, as alternativas de ocupação para os homens eram maiores. Enquanto eles estavam presentes em quase todas as atividades ocupadas pelas mulheres, como a costura de sacos ou nas maçaroqueiras, vários trabalhos eram interditados a elas, principalmente os cargos de chefia. (RAGO, 1997, p. 65)

Nesse cenário, marcado pela incipiente industrialização e urbanização do país, emergem os movimentos operários que, mesmo já contando com um expressivo percentual de mulheres e crianças nas indústrias, vão ser liderados por homens. Os movimentos, gestados nos primeiros anos do século XX, defendiam o retorno das mulheres ao lar, compreendendo que era competência feminina o zelo pela casa e pela dedicação à maternidade e cuidados com os filhos e marido. Com isso, a mobilização do movimento operário, na época, contribuiu significativamente para assegurar a divisão sexual do trabalho, pautada em assimetrias e hierarquizações.

Episódios como esse demarcaram a posição dos homens e das mulheres no mundo do trabalho e garantiram os privilégios, status e ocupações diferenciadas na esfera produtiva. O resultado foi uma completa desvalorização, desqualificação e inferiorização dos postos de trabalho ocupados por mulheres, na atualidade.

\section{O trabalho feminino no contexto da reestruturação produtiva}

Com as mudanças culturais, sociais, políticas e econômicas, as mulheres passaram a ocupar os espaços públicos e os principais fatores que contribuíram para a inserção feminina no mundo do trabalho foram o aumento do nível de escolaridade, gerando novas oportunidades empregatícias, a queda da fecundidade e o crescimento de famílias monoparentais femininas.

Mesmo com elevados níveis de escolarização, as mulheres ainda possuem 
remuneração diferenciada em relação aos homens e também prevalecem em determinados "guetos ocupacionais femininos", com destaque para a educação e a saúde, conforme análise de Bruschini e Lombardi (2002, p. 171). As autoras relatam que alguns setores econômicos têm gerado maiores oportunidades para as mulheres, como o de prestação de serviços, o agropecuário, o social, o comércio de mercadorias e o industrial, com destaque para o setor têxtil.

Do ponto de vista da disparidade salarial entre homens e mulheres, alguns fatores podem ser ressaltados, pois, em relação às mulheres,

(...) o fato de terem ingressado no mercado formal de trabaIho nas três últimas décadas - o que as colocou no olho do furacão da reestruturação produtiva do capital, alocando-as em relações de trabalho precarizadas -; de representarem $38 \%$ das chefias familiares; de almejarem melhorar a cesta e a receita familiar, garantir o estudo dos filhos e tomar a abertura social promovida pelos movimentos populares e pelas lutas feministas faz com que elas aceitem trabalhar por salários mais baixos. (CRUZ, 2006, p. 317)

Portanto, alguns aspectos justificam a significativa inserção da mão de obra feminina no espaço da produção, devido à pressão econômica e à geração de novas necessidades e desejos, que estimularam o consumo em um quadro de empobrecimento dos/as trabalhadores/as, que passaram a arcar com despesas como as políticas de educação e saúde, frente ao sucateamento e insuficiência dos serviços sociais públicos sob a chancela do Estado neoliberal.

Mesmo com a abertura econômica, a qual provocou queda na produção e desemprego, as mulheres continuaram a incorporar o mundo do trabalho, porém, em um cenário marcado pelo estímulo à terceirização da economia, o que gerou formas de trabalho precárias e informais.

Esse quadro deve ser enfatizado, pois,

(...) as mulheres parecem estar se beneficiando mais do que os homens das novas oportunidades de emprego criadas. Tal constatação sugere, desde logo, um comentário: mais chances em meio a um quadro menos promissor, mais instável e mais desprotegido (LAVINAS, 2000, p. 139).

Sob esse prisma, Hirata (2002, p. 148) atesta que ocorreu uma bipolarização no mundo do trabalho, no findar do século XX, tanto nos países europeus desenvolvidos, quanto, por exemplo, no Brasil, envolvendo as mulheres; pois, de um lado, se observam profissionais altamente qualificadas, que ingressam em postos 
de trabalho com salários relativamente bons - como as médicas, advogadas, professoras, engenheiras, arquitetas, dentre outras, que correspondem, em média, a $10 \%$ do contingente das trabalhadoras; e, no outro extremo, trabaIhadoras com baixa qualificação, menores rendimentos e ocupando posições na esfera produtiva sem reconhecimento, status e prestígio social. Portanto, formou-se um conjunto de trabalhadoras com perfis extremamente opostos: de um lado as executivas e intelectuais, de outro as subcontratadas, temporárias e sazonais, que vivem e sobrevivem em condições precárias, degradantes e incertas no cenário das sucessivas transformações societárias que se expressam na reestruturação produtiva, caracterizada pela flexibilização das relações de trabalho que provoca consequências danosas ao conjunto da população em face da precarização do trabalho, que,

(...) vem se ampliando cada vez mais, na medida em que cresce consideravelmente a nova estrutura industrial de cadeias de subcontratação. As grandes e modernas empresas vêm adotando formas de trabalho informal e mal pago, ressaltando-se o trabalho a domicílio realizado majoritariamente pelas mulheres, reproduzindo as desigualdades das relações de gênero. (NEVES, 2000, p. 180)

Com isso, verifica-se que o ingresso das mulheres no mundo do trabalho traz consigo as marcas da precariedade, o que apontam Bruschini e Lombardi (2002, p. 174), ao constatarem que o trabalho doméstico, conhecido como um "nicho feminino por excelência", incorpora mais de $90 \%$ de mulheres.

Com base nos apontamentos de Hirata (1998, p. 13), no Brasil, a difusão das inovações organizacionais e tecnológicas, no decurso dos anos 1980 e 1990, ocorreu de forma desigual, afetando, principalmente, as grandes empresas e o contingente de trabalhadores qualificados do sexo masculino. As trabalhadoras continuaram sendo controladas pelas formas de organização do trabalho de matriz taylorista, submetidas a cadências e ritmos apregoados pela linha de montagem. Isso pode ser visualizado nas indústrias de calçados e da confecção/ vestuário, onde a presença do controle do tempo, dos ritmos e da produtividade se faz atual, sendo questionável atestar para o fim ou substituição dos modelos de produção de base taylorista/fordista.

Tomando como parâmetro o universo da confecção, cabe sublinhar que o mercado de trabalho nesse setor é nitidamente sexuado, estruturado na divisão sexual, pois a predominância feminina é notória e abrange todas as funções, desde a modelista até a costureira. Nesse ramo de produção, o último elo da cadeia produtiva é a trabalhadora domiciliar, que realiza suas atividades na própria residência e presta serviços às empresas que contratam seus serviços. 
Essa modalidade de trabalho não é recente, pois c om a Revolução Industrial, no século XVIII, o trabalho domiciliar assume novas feições e passa a ser composto, majoritariamente, pelo trabalho feminino. O que caracteriza o trabalho domiciliar e o diferencia do trabalho doméstico é o seu caráter remunerado, que acontece no espaço da casa, diferente da atividade doméstica, realizada, em sua maioria, pelas mulheres, ao cuidar das tarefas do lar, dos filhos e do marido, sem haver remuneração. Sendo uma atividade executada no espaço residencial, o trabalho domiciliar ganha status de invisibilidade e clandestinidade. Abreu e Sorj (1993, p. 23), pontuam que o trabalho domiciliar “(...) sempre se apoiou no trabalho doméstico e na divisão sexual do trabalho, tanto na esfera da produção, como na da reprodução".

Esse tipo de atividade também sempre serviu como sustentáculo do sistema reprodutivo e acumulativo do capital e, mesmo sendo freado, em alguns momentos do desenvolvimento da indústria, ele não desapareceu, estando sempre presente na lógica concorrencial.

Conforme argumentação de Abreu (1986, p. 69), nos primeiros decênios do século XX, o trabalho domiciliar ficou restrito a determinados setores produtivos, mas ainda com presença maciça do contingente feminino. Dentre os setores que não aboliram o trabalho a domicílio, ao longo do tempo, mas ao contrário, aumentaram consideravelmente a prática dessa atividade, destacam-se os ramos da confecção/vestuário e de calçados.

Contudo, o trabalho domiciliar ganha maior destaque na segunda metade do século XX, diante do processo de reestruturação produtiva que prevê a adoção de formas flexíveis de trabalho, desencadeando um processo intensificado de terceirização, que resultou em informalidade, subcontratações e precarização. Dentre os setores que incorporaram o trabalho em domicílio, destacam-se o têxtil, calçados, confecção, couro, madeira, embalagens, alimentos, dentre outros que requerem, em sua maioria, a "habilidade e destreza" femininas.

Esse quadro pode ser verificado na realidade brasileira diante de alguns estudos realizados nas últimas décadas, em que se constatam os processos de terceirização na produção do calçado, como acontece no Rio Grande do Sul, em especial no Vale dos Sinos e na cidade de Franca, no interior do Estado de São Paulo².

Tal realidade também está presente no complexo têxtil e indústrias da confecção/vestuário, como se observa no município de Divinópolis, região Centro-Oeste do Estado de Minas Gerais, a região de Campinas, no Estado de São Paulo e outros estados brasileiros como Goiás e Paraná, a partir de alguns estudos realizados nessas regiões e localidades ${ }^{3}$.

A partir desse esboço, as mulheres, trabalhadoras a domicílio, sob formas

2. Para obter informações mais consistentes sobre o assunto, recomenda-se consultar a obra de Navarro (2006).

3. Cabe destacar os estudos de Lima (2006) sobre a realidade da confecção em Goiás, a pesquisa de Araújo e Amorim (2002), na região de Campinas-SP, a análise de Lima (2009) na região de Cianorte no Estado do Paraná e, também, as contribuições de Neves e Pedrosa (2007) sobre Divinópolis-MG. 
4. Dados disponíveis no site da OIT no período mencionado. Site: http://www. oit.org.br subcontratadas e informais de trabalho, ficam fragilizadas, submetidas a extensas jornadas de trabalho, isoladas no espaço doméstico, sem representação coletiva/sindical, produzindo de acordo com as necessidades da demanda do contratante, recebendo salários baixos que são estipulados por peça e sem amparo da legislação trabalhista.

Assim, o trabalho a domicílio passa a ser o lócus de confinamento das mulheres, sob os caracteres da insegurança no trabalho, do desprestígio, do isolamento e da segregação ocupacional expressa nas relações de gênero. Isso resulta em dificuldades no que tange à mobilidade social do sujeito feminino e reforça as assimetrias ocupacionais e salariais entre homens e mulheres.

Outro aspecto a ser enfatizado é o processo de reestruturação e flexibilização do trabalho, que ocorre de forma sexuada, garantindo aos homens ocupações e postos de maior qualificação, prestígio e melhores salários em detrimento da inserção feminina em atividades flexíveis e subcontratadas, marcadas por baixos salários e menores exigências de qualificação. Outro elemento importante se refere ao quadro de desemprego e de precarização das formas de contratação, que contribuem para engendrar um sentimento de impotência, de fragilização, instabilidade, segmentação do coletivo, descrenças, insatisfações e medo nos trabalhadores, tendo em vista a dificuldade de manutenção nos postos de trabalho e a necessidade da garantia de sobrevivência daqueles que vivem e sobrevivem da venda da força de trabalho.

Esse quadro se faz evidente tendo em vista os dados divulgados pela Organização Internacional do Trabalho (OIT), no ano de $2009^{4}$, revelando um aumento exponencial do desemprego no mundo, que atingiu 6,6\% da população economicamente ativa. Segundo foi constatado, o índice de desemprego, de 2007 para 2009, teve uma progressão de 0,9\%. Conforme as informações divulgadas, se verifica, também, um aumento significativo dos trabalhos precários que passa a atingir $50,6 \%$ da força de trabalho global, ou seja, mais da metade dos/as trabalhadores/as encontram-se sob o regime de ocupações precarizadas.

No que tange ao desemprego feminino, a OIT divulgou, em 2007, uma taxa mundial de $6,4 \%$ entre as mulheres, em detrimento de 5,7\% para os homens. Em relação ao Brasil, o desemprego masculino, no ano de 2007 , foi de $6,2 \%$, enquanto o feminino ficou em $10,1 \%$, o que explicita, também, um expressivo contingente de mulheres atingidas pelo desemprego, em detrimento dos homens, acirrando as disparidades de gênero no mundo do trabalho e exigindo debates qualificados diante da sustentação da divisão sexual do trabalho na contemporaneidade, em que se apregoa, por meio de mecanismos ideológicos, a concepção falaciosa de que vivemos em uma sociedade igualitária, sem distinção e discriminação de classe, gênero, raça/etnia, credo e sexo. 
$\mathrm{Na}$ atualidade, o mundo do trabalho se orienta por tempos precarizados, absorvendo sobremaneira o contingente feminino, o que se reflete nas relações sociais de gênero e na sustentação da divisão sexual do trabalho, desmistificando a concepção de que, atualmente, vivemos em uma sociedade democrática, igualitária e justa, sem discriminação e preconceitos de gênero, raça/etnia, credo, sexo, dentre outros. O que se constata é o contrário, pois as formas de discriminação e preconceito, tanto no espaço público/produtivo, quanto no espaço privado/reprodutivo permanecem contribuindo para a manutenção de formas segregacionistas, a persistência das desigualdades de gênero e a divisão sexual do trabalho. Conforme aponta Kergoat (2009, p. 67-68), a divisão sexual do trabalho é resultado das relações sociais de sexo e não pode ser vista como uma construção rígida, determinista e imutável, pois, para a autora, a partir de uma reflexão dialética, tendo como horizonte as rupturas, permanências e superações, suas modalidades variam no tempo e no espaço, mesmo que seus princípios organizadores permaneçam os mesmos. Sob esse prisma da dialética, de acordo com a ela, é importante questionar a própria existência da divisão sexual do trabalho ${ }^{5}$.

Nesse sentido, deve-se destacar que são inegáveis as transformações gradativas ocorridas no campo da cultura, da política e da economia nas últimas décadas, em especial no que tange ao acesso das mulheres ao mundo do trabalho, às políticas sociais, como saúde e educação, inserção na esfera pública, dentre outras.

Por isso, ao apreender as relações de gênero neste atual estágio de transformações, com destaque para o mundo do trabalho sob o ideário do complexo de reestruturação produtiva, vale ressaltar que, no último quartel do século $X X$, é notória a expansão e incorporação da mão de obra feminina nos processos produtivos, o que ficou denominada, de acordo com Nogueira (2004), por uma feminização nesse cenário, pois as mulheres passaram a ocupar postos de trabalho outrora destinados somente aos trabalhadores homens. É importante abrir um parêntese para esse período, pois, além do ingresso significativo das mulheres no mundo do trabalho, ocorreu também a organização política e sindical desse segmento populacional, passando estas a terem uma participação mais efetiva nas lutas coletivas. Os principais objetivos dessas lutas eram a busca pela igualdade no trabalho no que tange aos salários, ocupações e garantias sociais, além de reivindicarem a divisão sexual em prejuízo ao grupo feminino submetido à dupla ou tripla jornada de trabalho. Dessa forma, questões pertinentes às mulheres, que, até então, estavam no reduto privado, ganham visibilidade e passam a ser publicizadas. Com isso, as mulheres ingressam no cenário brasileiro como sujeitos políticos reivindicando direitos e reconhecimento.

Nesse conjunto de acontecimentos,
5. Este texto tem o intuito de apresentar reflexões e questionamentos sobre a manutenção da divisão sexual do trabalho na atualidade, em um contexto no qual se apregoa uma suposta igualdade nas relações de gênero, ocultando as desigualdades, assimetrias e hierarquias vigentes no capitalismo contemporâneo. Neste caso, o respectivo texto problematiza tal situação com enfoque na cadeia produtiva da confecção. Tal objetivo, nos seus respectivos limites, se inspirou na ideia de Ricardo Antunes (2007), que, em sua obra Adeus ao Trabalho?, lançou resposta à obra de André Gorz (1987), que atestava para o fim do trabalho e do proletariado. Segundo Antunes (2007), nos últimos tempos, com o advento da reestruturação produtiva e do neoliberalismo, o que se observam são metamorfoses no mundo do trabaIho e não a perda da sua centralidade. 
6. Tais dados são resultantes de pesquisas realizadas $\mathrm{e}$ tabuladas pelo autor no site da RAIS no respectivo período mencionado. Site consultado: http:// www.rais.gov.br
(...) a presença de mulheres na cena brasileira foi expressiva, denunciando as situações de desigualdade a que estavam submetidas e manifestando de várias maneiras a reivindicação de seus direitos. O ano de 1975 foi marco importante dessa mobilização ao ser escolhido como Ano Internacional da Mulher pela ONU. No Brasil, a luta pela valorização da identidade feminina denunciando as condições de subordinação das mulheres integra-se à luta pela redemocratização do país no final dos anos 70. (NEVES, 2000, p. 173)

Cabe ressaltar que as mulheres ocuparam, principalmente, os espaços de trabalho mais precarizados e, mesmo nos espaços da produção, não abandonaram suas atividades no âmbito da reprodução, ou seja, mantiveram suas tarefas domésticas de cuidado do lar e dos filhos, reforçando a divisão sexual do trabalho, entendida como construto social e presente nas relações sociais estabelecidas entre homens e mulheres a fim de garantir interesses e poder.

Com a divisão social e sexual do trabalho, ocorre uma polarização das qualificações masculinas e femininas, visto que os homens ocupam majoritariamente determinados postos de trabalho, como é o caso da siderurgia e metalurgia, enquanto as mulheres ocupam setores como o têxtil, o comércio, dentre outros marcados pela informalidade e terceirização. Isso pode ser constatado com base em pesquisa realizada no município de Divinópolis, na região centro-oeste de Minas Gerais, que se destaca economicamente pela produção confeccionista/ vestuário e pela indústria metalúrgica. Os dados da Relação Anual de Informações Sociais (RAIS), do ano de $2008^{6}$, apontam que, no município, dos/as empregados/as formais no setor da metalurgia, 7\% eram mulheres e 93\% homens. Já na indústria da confecção/vestuário, neste mesmo município, havia a incorporação de $73 \%$ de mulheres e $27 \%$ de homens no setor, reforçando e sustentando as bases da divisão sexual do trabalho. Ainda como critério para tais ocupações sustenta-se o discurso do trabalho pesado para os homens e do trabalho leve para as mulheres, ou seja, relaciona a força física, a coragem, os trabalhos sujos e insalubres como atributos masculinos e sinônimos de virilidade em contraposição aos trabalhos delicados e leves ligados aos atributos femininos.

Na indústria da confecção, particularmente, são apresentadas distribuições nas ocupações que reforçam a divisão sexual do trabalho, pois, em geral, algumas funções são destinadas aos homens, como, por exemplo, o corte, considerada uma atividade mais pesada, enquanto a costura fica sob a responsabilidade das mulheres. Nessas atividades, o corte exige uma menor quantidade de trabalhadores/as, enquanto a costura requer um contingente maior de força de trabaIho, o que justifica o predomínio de mulheres nessa cadeia produtiva. 
Tal realidade reforça os espaços ocupacionais de homens e mulheres no mundo do trabalho que são, muitas vezes, associados à força física e demais habilidades que servem como mecanismos para solidificar relações de gênero hierarquizadas.

Nesse aspecto, Hirata e Kergoat (2007, p. 596) argumentam que a divisão sexual do trabalho se aplica nos estudos sobre a distribuição diferenciada das ocupações e profissões de homens e mulheres no mundo do trabalho e também no trabalho doméstico. Com isso, o que se verifica são desigualdades e assimetrias sistemáticas nas relações sociais entre os sexos que criam o sistema de gênero. Nesse sentido, as autoras ponderam que surge o princípio hierárquico que superioriza, qualifica e valoriza o trabalho masculino em detrimento da inferiorização, desqualificação e desvalorização do trabalho feminino e o princípio de separação em que há trabalhos específicos e próprios para homens e trabalhos direcionados às mulheres.

Hirata (2002) indaga que a questão da divisão sexual do trabalho passa a ganhar evidência e ser problematizada nos anos 1980 e aponta que,

A divisão sexual do trabalho é considerada como um aspecto da divisão social do trabalho, e nela a dimensão opressão/dominação está fortemente contida. Essa divisão social e técnica do trabalho é acompanhada de uma hierarquia clara do ponto de vista das relações sexuadas de poder. (p. 280)

Tal fenômeno não é recente, pois a divisão social e sexual do trabalho perpassa os diversos estágios da humanidade, sendo que as mulheres de todas as camadas sociais, livres ou escravas, estiveram, no decorrer da história, restritas à esfera doméstica, pois respondiam pela subsistência de seus grupos. Esse formato hierarquizado e assimétrico atravessou a história da humanidade nos diversos períodos e, a partir do século XVIII, com a Revolução Industrial, o capitalismo se consolida em face da divisão de classes e da intensificação da industrialização, urbanização e concentração da propriedade privada. Com isso, ocorreu um intenso fluxo migratório do campo para a cidade e surgiu o proletariado fabril para o trabalho nas fábricas, que incorporou o contingente feminino como representante do conjunto de trabalhadores/as assalariados/as.

Mesmo com o ingresso das trabalhadoras no ramo fabril, a partir da industrialização, as relações sociais entre homens e mulheres permaneceram desiguais e assimétricas, como foram historicamente construídas e legitimadas, com as marcas da cultura patriarcal de subordinação. Além da inserção feminina no mundo do trabalho no que tange à esfera da produção, as tarefas domésticas e familiares, ou seja, o espaço da reprodução continuou reservado às 
mulheres, o que se sustenta até os dias atuais e reforça o lugar naturalizado das mulheres no sistema social.

Se a persistência da responsabilidade das mulheres pelos cuidados com a casa e a família é um dos fatores determinantes da posição secundária ocupada por elas no mercado de trabalho, a maternidade é, sem dúvida, o que mais interfere no trabalho feminino quando os filhos são pequenos. A responsabilidade pela guarda, cuidado e educação dos filhos na família limita a saída da mulher para o trabalho remunerado, sobretudo se os rendimentos obtidos forem insuficientes para cobrir custos com formas remuneradas de cuidado infantil. (BRUSCHINI, 2000, p. 19)

Tal preceito é verificado mesmo com as transformações na estrutura familiar nos últimos tempos, pois, diante de inúmeras alterações ocorridas nesse grupo, as atribuições femininas e masculinas no âmbito privado, ou seja, na esfera doméstica, permanecem os homens como responsáveis pelo provimento das necessidades materiais dos componentes do lar e as mulheres, sob a incumbência de zelar pelas tarefas de cuidado dos filhos e da casa. Mesmo que as mulheres tenham um trabalho na esfera da produção, este é visto como complementação ao orçamento familiar.

Hirata (1998, p. 17) destaca que, na fase atual de crise estrutural capitalista e do processo de reestruturação produtiva, a atividade feminina passou por uma ampliação, sendo que, ao mesmo tempo em que se verifica o crescimento da taxa da atividade feminina, também se expande a precarização do emprego, seja pelo incremento do trabalho em tempo parcial, seja pela intensificação da informalidade.

Para apreender tais acontecimentos presentes nas relações sociais, seja na esfera do trabalho, da família e das classes sociais é necessário extrapolar o âmbito dos setores de atividade e as ocupações em geral, pois as correlações de força e as estruturas de poder estão presentes nas relações de gênero, sendo esses mecanismos legítimos não só no âmbito do trabalho, mas também nas outras esferas que perpassam as formas de sociabilidade do conjunto da população; seja no espaço privado (doméstico/família) ou no público (sociedade como um todo).

Diante disso, no quadro da era flexível,

As mulheres são as primeiras vítimas do paradoxo do crescimento do emprego feminino num contexto de crise: menores salários, maior instabilidade, condições de trabalho 
acumulando atividades domésticas e profissionais, maior desemprego, impactos previsíveis sobre a saúde. (HIRATA, 1998, p. 19)

O que se verifica são medidas adotadas no contexto da crise do capital, de reestruturação produtiva, neoliberalismo e flexibilização, que assolam o plano econômico e ideopolítico, atingindo todos os países capitalistas, o que tem desencadeado profundas alterações dos estatutos jurídicos no campo do trabalho. É importante considerar que tais mecanismos ocorrem de forma diferenciada para o conjunto de trabalhadores homens e mulheres, pois a segregação ocupacional perpetua-se diante de uma sociedade sexista e patriarcal, que define as mulheres como força de trabalho de alto custo e complementar, tendo em vista a questão da maternidade e da reprodução. Assim, pode-se observar que a reestruturação produtiva teve implicações e efeitos diferenciados para homens e mulheres, não alterando, significativamente, a divisão sexual do trabalho, visto que as mulheres permanecem em posições desvantajosas.

Nesse quadro atual, o que se tinha como estável e perene no mundo do trabaIho, diante da garantia de uma legislação trabalhista, planos de carreira, empregos vitalícios e direitos sociais, agora se vivencia um estágio caracterizado por incertezas, inseguranças e instabilidades na inserção, ocupação e manutenção no espaço produtivo frente ao processo de desregulamentação, flexibilização e deterioração do trabalho, que trazem rebatimentos para a saúde física e mental do/a trabalhador/a.

No Brasil, apesar da escassez de uma base de dados estatísticos acerca do contingente feminino nos trabalhos informais, terceirizados, subcontratados e precários, inúmeros foram os estudos já realizados que apontam para a predominância das mulheres nesses tipos de atividades, tendo em vista a necessidade de conciliar as tarefas da reprodução com a produção, o que poderia apontar para uma reestruturação e flexibilização sexuada do trabalho, que determina o lugar e a posição das mulheres no sistema social vigente ${ }^{7}$.

Perante tal conjuntura, observa-se que o mundo do trabalho, na atualidade, se estrutura em tempos precarizados e sexuados nas suas relações de produção, diante de postos de trabalho instáveis e oscilantes às prerrogativas do capital e de baixo custo da mão de obra feminina, refletindo em diferenças salariais entre homens e mulheres, em diversos ramos produtivos, como é o caso do setor da confecção/vestuário.
7. Considera-se que há bancos de dados sobre o trabalho formal em âmbito nacional e internacional, como por exemplo, a RAIS/ CAGED, OIT, dentre outros. Porém, quando refere-se aos dados sobre o trabalho informal, flexível e terceirizado, ainda é muito difícil realizar um mapeamento dessa realidade diante de atividades clandestinas e ilegais. Mesmo com tal ausência, o que se verifica é um processo de feminização nas atividades informais, terceirizadas e precarizadas, tendo em vista os diversos estudos e pesquisas sobre o assunto, tanto em âmbito nacional, quanto em âmbito internacional. Dentre a produção bibliográfica, destacam-se: Hirata (1998; 2002), Neves (2000; 2006), Lavinas (2000), Nogueira (2004), Lima (2009), Abreu e Sorj (1993), Maruani, Rogerat e Torns (2001), Rivas e Rodríguez (2008), Torns (1999), Candela Soto (2008), Díaz Valero (2008) e outros. 
A cadeia produtiva da confecção acompanhou, nos últimos anos, as transformações na organização e gestão do trabalho em um contexto marcado pela flexibilização produtiva, ou seja, arranjos foram estruturados, dentro da dinâmica do capital financeiro, o que provocou uma intensificação de formas externalizadas de algumas fases da produção. Com isso, o mundo do trabalho atualizou formas de trabalho pautadas em atividades temporárias, domiciliares e precárias, que se tornaram funcionais aos anseios do desenvolvimento capitalista.

Esses direcionamentos no mundo do trabalho são verificados, no caso brasileiro, em especial a partir da década de 1990, diante da acentuada crise econômica desencadeada pela abertura comercial estimulada pelo Governo Collor, a qual resultou em um período de recessão e falência de importantes e grandes indústrias, que não conseguiram o nível de competitividade com os padrões do mercado externo. Isso foi observado, também, nas indústrias da confecção, que sofreram os rebatimentos desse processo, pois a entrada de produtos importados no mercado interno, com destaque para roupas e tecidos em volume elevado e a baixos preços, implicou na redução, suspensão ou, até mesmo, na falência de indústrias na respectiva época. Dentre vários motivos, a baixa capacidade tecnológica no setor pode ser considerada como um elemento que dificultou a competitividade com o mercado externo.

Como resposta à crise instaurada, o processo de reestruturação produtiva e a adesão às prerrogativas neoliberais desencadearam um acelerado movimento de externalização da produção industrial utilizando, intensivamente, as formas de subcontratação e o trabalho domiciliar. As medidas tiveram como principais razões a busca empresarial por flexibilização da produção e das relações de emprego, com vistas a redução de custos, como estratégia de competitividade, contribuindo para o enxugamento do trabalho formal, realizado no espaço interno das fábricas e proporcionando o crescimento de pequenas e microempresas, além de estimular a informalidade, que pressupõe atividades,

(...) nas quais as relações de trabalho não obedecem à legislação trabalhista. em se tratando da legislação fiscal, o que caracterizaria essas ocupações seria a ilegalidade, pois estão à margem do sistema tributário. (...) A heterogeneidade do trabalho na informalidade incorpora assimetrias com relação à renda, pois é possível encontrar desde trabalhadores com excelente nível de renda, uma minoria, até aqueles cuja remuneração mal garante o consumo mínimo necessário para si e sua família, e que são maioria. (LIRA, 2002, p. 143)

Nesse cenário de reorganização, externalização e deslocamento territorial das atividades produtivas, a partir do impulso às formas de subcontratação, 
pôde-se verificar empresas multinacionais atuando em dimensão mundial, com sede em um determinado país e controlando seus processos de produção em diversas localidades onde se encontram os prestadores dos serviços, os quais, submetidos a essa cadeia "global", tornam-se destituídos de garantias legais, sociais e previdenciárias, em condições precárias de trabalho.

Nesse ínterim, cabe mencionar que, no complexo têxtil, com destaque para a indústria da confecção, ocorreu, a partir dos últimos anos do século XX e início do século XXI, no Brasil, um significativo deslocamento territorial das unidades produtivas, principalmente do Sudeste para o Nordeste, tendo como principais aspectos estimuladores os menores custos da força de trabalho, os incentivos fiscais e creditícios. Basta confirmar essa realidade a partir de alguns dados divulgados pelo Instituto de Estudos e Marketing Industrial (IEMI), pois a região Nordeste, em 1990, representava, em volume, $13,3 \%$ da produção nacional da indústria têxtil e de vestuário, passando para 20,6\%, em 2001, enquanto a região Sudeste reduziu sua participação de 56,8\%, em 1990, para 47,5\%, em $2001^{8}$.

A política de desenvolvimento adotada na região Nordeste, em especial, se respaldou na adoção de práticas terceirizadas e implantação de cooperativas, como estratégias de evitar os encargos sociais previstos na legislação trabalhista. Introduzir essa modalidade de produção em determinadas regiões foi uma estratégia fundamental de atendimento às prerrogativas de acumulação capitalista, com seu escopo de maximização de lucros e exploração do trabalho, pois o baixo custo da força de trabalho se torna atrativo aos empregadores, visto que, para esse segmento, os gastos com salários e encargos sociais previstos na legislação significam um empecilho para a geração de empregos e compromete a competitividade da indústria brasileira no mercado interno e externo.

Nesse raciocínio, os empregadores buscam estratégias de migração de suas unidades produtivas para os espaços geográficos, onde não há um sindicalismo organizado e combativo, para que possam subjugar as relações e condições de trabalho aos seus imperativos.

O ordenamento instaurado a partir do deslocamento industrial para outras regiões repercutiu substantivamente na vida dos trabalhadores, pois implicou em expansão do desemprego nas localidades de maior custo da mão de obra, enfraquecimento do poder sindical e precarização das relações de trabalho.

Esse movimento foi analisado por Araújo e Amorim (2002) na região de Campinas, estado de São Paulo, comprovando que, nos anos 1990, ocorreu uma redução expressiva das indústrias de confecção, tanto as de médio, quanto as de grande porte, sendo que as autoras apontam que a única empresa de grande porte existente naquela localidade foi fechada nesse período.
8. Os respectivos dados estão disponíveis no site: http://www.iemi. com.br/biblioteca/ textilhttp://www. iemi.com.br/biblioteca/textil 
Além do deslocamento territorial, foram criadas alternativas pelas empresas no que concerne ao atendimento dos interesses de acumulação e manutenção do capital e a principal medida implementada foi a terceirização, tida como uma estratégia de competitividade, que significa a transferência de partes ou, até mesmo, de todas as atividades de produção para "terceiros", ou seja, micro, pequenas empresas ou trabalhadores autônomos assumem as responsabilidades com os procedimentos a serem executados em um determinado prazo e na devida quantidade solicitada. A prática estabelecida não é caracterizada por vínculos empregatícios, fugindo do aparato da legislação que regula as relações de trabalho. Porém, existe um contrato informal pautado no compromisso da entrega do produto com prazos e quantidades estipuladas que dependem dos fluxos de mercado.

Por isso, esse tipo de contrato pode ser rompido a qualquer momento, trazendo prejuízos aos/as trabalhadores/as prestadores de serviços. Em síntese, no contexto da acumulação flexível, a terceirização objetiva reduzir custos e maximizar lucro.

No Brasil, foram adotadas duas modalidades de terceirização, constituídas da seguinte forma,

(...) a primeira, considerada mais virtuosa, consiste num instrumento de melhoria da qualidade, da produtividade e da competitividade, na medida em que inovações tecnológicas e organizacionais são transferidas para as empresas subcontratadas e se difundem ao longo da cadeia. Na segunda modalidade, a terceirização ocorre com o objetivo central de redução de custos e, nesta medida, o que se transfere às subcontratadas são os gastos e os riscos da produção e o custo da mão-de-obra. Neste caso, a exigência de preços baixos dá-se, muitas vezes, em detrimento da qualidade. E é esta segunda modalidade que, segundo vários estudos, tem se generalizado no país com consequências danosas para os trabalhadores nelas envolvidos. (ARAÚJO \& AMORIM, 2002, p. 274)

Dentre os ramos da cadeia produtiva que adotaram tais procedimentos, é nítido o caso da indústria da confecção, setor caracterizado, ainda, por uma tecnologia rudimentar e com uso intensivo da força de trabalho, pois a produção consiste na utilização da máquina de costura industrial e do trabalho manual, com forte incorporação do trabalho domiciliar feminino pautado no regime da subcontratação.

Vale sublinhar que, desde sua origem, o setor econômico confeccionista 
tem adotado essas respectivas práticas em suas atividades produtivas, ou seja, o trabalho domiciliar e subcontratado na indústria da confecção não são recentes, mas remontam aos seus primórdios e sofreram modificações ao longo do tempo, de acordo com as prerrogativas do capital, no que tange à sua reprodução e acumulação. Além do mais, o setor da confecção tem utilizado e revitalizado formas terceirizadas, o que reflete nas condições precárias de trabalho do segmento envolvido na cadeia produtiva, pois os/as trabalhadores/as passam a assumir os gastos e riscos da produção.

Diante disso, vale destacar que o trabalho domiciliar subcontratado ganha significativa importância na sustentação dessa cadeia produtiva, mediante a redução de custos no que tange ao ônus com aluguel, maquinário e com a força de trabaIho, devido aos encargos sociais, pois os/as trabalhadores/as subcontratados/as não são assegurados/as de nenhum direito trabalhista no que se refere à previdência social, férias, décimo terceiro salário, licença maternidade, fundo de garantia, dentre outros. Além do mais, adotar o trabalho domiciliar, em regime de subcontratação, permite a flexibilidade dos contratantes, considerando que muitos recorrem aos/as trabalhadores/as externos/as somente nos momentos de aquecimento econômico.

Outro elemento importante que merece destaque se refere aos principais momentos de pico e elevação da produtividade no âmbito da indústria da confecção/vestuário que se concentram em datas comemorativas e festivas como o Natal e também a estação de inverno. Nesses períodos, pode ocorrer a quarteirização, ou seja, os/as trabalhadores/as domiciliares subcontratam outros/as trabalhadores/as para o auxílio na produção por um tempo determinado.

Além do mais, com base na pesquisa realizada por Neves (2006, p. 260), apesar do expressivo contingente feminino incorporado nesse setor da economia, algumas fases são executadas por homens. Segundo a autora, o processo de produção do vestuário passa pelas seguintes etapas: “(...) criação de modelos, elaboração de moldes, infesto, corte, costura, estamparia e acabamento" (p. 260) e, dentre tais fases, há um predomínio do trabalho masculino nos procedimentos do infesto e do corte, que também requer maior qualificação. Com isso, se verifica que

(...) os novos postos criados pela microeletrônica, sobretudo na oficina de corte, permitiram a entrada de homens operários de alta qualificação no ramo: são postos que exigem um tempo de aprendizado formal mais longo e um senso de responsabilidade, podendo os erros representar custos onerosos para a produção. Por isso são mais bem pagos. (HIRATA, 2002, p. 210)

Já a costura, o acabamento e estamparia, tarefas consideradas de baixa 
qualificação e repetitivas, são as etapas com maior contingente feminino e que mais se utilizam do trabalho terceirizado, sob as marcas da informalidade e da precarização. Diante disso, observam-se, na indústria da confecção, as assimetrias nas relações de gênero que se refletem em todo o mundo do trabalho.

A costura, etapa do processo produtivo que ocupa a maior parte do trabalho, (...) é realizada por mulheres, na informalidade, e tarefas como administração, criação, infesto e corte tem uma maior participação masculina, permanecendo como trabalho formal. Mantidas as atuais tendências, os homens devem concentrar-se no topo da cadeia, em tarefas administrativas, de comando, de maior qualificação e, consequentemente, com melhor remuneração. E as mulheres permanecerão na ponta da cadeia, realizando o trabalho informal, taylorizado, marcado pela monotonia, repetição e desqualificação. (NEVES, 2006, p. 264)

O que se nota é que os homens se apropriaram das atividades mecânicas, técnicas e qualificadas, enquanto as mulheres ficam confinadas às tarefas manuais, simples e rotineiras. Nesse aspecto, Hirata (2002, p. 211-212), ao tratar da indústria têxtil, enfatiza que,

(...) a desqualificação resultante das novas tecnologias leva à expulsão da mão-de-obra feminina, presente anteriormente em um certo número de postos qualificados; o surgimento de novas qualificações, ao contrário, torna efetiva a entrada dos homens. Observa-se aqui, uma nova segregação dos postos segundo a qualificação e uma mudança da divisão sexual do trabalho no sentido de uma polarização anteriormente inexistente entre postos desqualificados femininos e postos qualificados masculinos.

Vale salientar que, em sua maioria, as atividades terceirizadas da costura e do acabamento são realizadas por facções, que são uma extensão da casa das costureiras, ou seja, as unidades produtivas passam a ser as residências das trabaIhadoras, mesclando trabalho em domicílio com tarefas domésticas.

Também é importante destacar que, na cadeia produtiva da confecção, apenas algumas etapas de fabricação do vestuário adotaram incrementos tecnológicos, como ocorreu na fase do desenho com a utilização do sistema CAD (Desenho Assistido por Computador) e no corte com a adesão ao sistema CAM (Manufatura Assistida por Computador). A incorporação técnico-científica ficou restrita 
às grandes empresas com maior índice de produtividade. Em relação aos demais processos produtivos como montagem e costura das peças, persistem formas de trabalho manuais e sem adesão tecnológica. Além do mais, os maiores investimentos no ramo da confecção, nos últimos tempos, se direcionam para o design dos produtos e o marketing.

Conforme abordado por Araújo e Amorim (2002, p. 296), as atividades externalizadas, geralmente, consistem na costura, no acabamento e embalagem, ou seja, as fases intensivas em mão de obra, pois a maioria das empresas tende a manter determinadas fases como o design, a modelagem, o encaixe e o corte no espaço interno.

Do conjunto de trabalhadores incorporados nesse ramo de atividade, as mulheres representam o maior contingente, por atenderem aos anseios empresariais, pois executar tarefas no espaço domiciliar torna-se, muitas vezes, um "atrativo" para elas, no sentido de conciliar as funções da produção com as da reprodução, ou seja, cuidam da casa, dos filhos e do marido, ao mesmo tempo em que se dedicam à atividade produtiva da costura. Isso pode ser confirmado de acordo com os dados divulgados, em 2008, pela Relação Anual de Informações Sociais (RAIS) sobre o trabalho na indústria têxtil, confecção/vestuário e artefatos de tecido no Brasil, englobando regiões, estados e municípios. Os indicadores revelam que, no Brasil, $62 \%$ da mão de obra empregada formalmente no setor é feminina, enquanto que os homens representam $38 \%$. Na região Sudeste, observa-se que não ocorre variação, pois as mulheres representam $61 \%$ da mão de obra incorporada no setor enquanto os homens são $39 \%$ da força de trabalho ${ }^{9}$.

Diante desse quadro, se observa que a divisão sexual do trabalho na confecção é algo evidente, pois predomina a ocupação por homens nos níveis hierárquicos mais elevados e na direção, que requer um número menor de força de trabalho. Já a costura, que demanda uma quantidade de mão de obra maior, verifica-se a absorção do contingente feminino, pois, considerando que esse processo ainda se configura na relação máquina de costura versus costureira, ou seja, pautada em uma defasagem tecnológica, a adoção às inovações técnicas são verificadas nas etapas anteriores à costura, "(...) através da utilização dos sistemas CAD nas fases de design, modelagem, gradeamento e encaixe, e de equipamentos de controle numérico na fase do corte" (ARAÚJO \& AMORIM, 2002, p. 278-279).

A partir da divisão social do trabalho e da especialização do trabalho coletivo, verificam-se alterações substanciais nas fases de produção do vestuário, pois, se, anteriormente, a costureira particular detinha todo o conhecimento do processo de confecção da roupa, se aproximando das formas artesanais, a partir da organização científica do trabalho que estabelece atividades parciais e fragmentadas, ou seja, taylorizadas, surgem as categorias profissionais responsáveis
9. Tais dados foram extraídos do site da RAIS no período mencionado. Site consultado: http:// www.rais.gov.br 
por determinadas etapas da fabricação de um produto, como é o caso da confecção representada por costureiras, arrematadeiras, cortadoras, modelistas, bordadeiras, dentre outras. Mas o que prevalece nesse ramo econômico é a utilização intensiva de trabalho, em especial nas pequenas e médias unidades produtivas, baseada na mão de obra das costureiras.

Diante de um intenso processo de desverticalização das empresas, a indústria da confecção, ao longo de seu desenvolvimento, adotou formas precárias de trabaIho, marcadas pela informalidade, com destaque para a utilização do trabalho a domicílio, predominantemente feminino e, nesse sentido, os principais elementos que caracterizam as ocupações informais são a deterioração e a precariedade nas condições de trabalho; as extensas e instáveis jornadas de trabalho, pautadas em níveis baixos de rendimento e ausência de direitos sociais e trabalhistas, em decorrência da não existência da carteira de trabalho no regime contratual.

Para Cacciamali (2000, p. 153), o tema da informalidade é complexo e heterogêneo e pode abarcar diversas ramificações da economia, como as atividades terceirizadas, as microempresas prestadoras de serviços, o comércio de rua e de ambulantes, o trabalho temporário, subcontratado e domiciliar, a sonegação fiscal, a contratação ilegal de trabalhadores assalariados que não são contemplados pelos direitos sociais e trabalhistas, dentre outros. A autora argumenta, sinteticamente, que o processo de informalidade pode ser representado pelos assalariados sem registro e pelos trabalhadores por conta própria (p. 166). No mais, a informalidade é parte constitutiva do sistema capitalista, visto que contribui diretamente para a reprodução e acumulação do capital, porém fica dependente das diretrizes tomadas pelo mercado regulamentado.

(...) a expansão de formas de contratação que implícita ou explicitamente burlam a legislação laboral têm efeitos, não apenas sobre o uso indiscriminado do trabalho, mas sobre a cidadania, pois os assalariados sem registro, por um lado não tem acesso a um conjunto de garantias sociais e por outro não compõem um corpo coletivo. Não têm direitos, nem obrigações. Soma-se a isso o fato de que essas contratações sonegam receitas ao Estado. (CACCIAMALI, 2000, p. 171)

É importante considerar que, paralelamente ao crescimento do trabalho informal e precário, se presencia o aumento do incremento da mão de obra feminina no mundo do trabalho, reforçando a concepção de uma inserção marginal e já excludente das mulheres na esfera produtiva, que se submetem aos ditames dos regimes contratuais caracterizados pela desregulamentação e flexibilização, sem garantias sociais e legais. A partir dessa constatação, Lima (2006, p. 309), ao retratar a funcionalidade do trabalho feminino e da população excedente, 
assegura que, no processo de reordenamento capitalista e acumulação flexível “(...) as mulheres são mobilizadas quando o capital necessita delas e retornam à vida doméstica quando se instaura a concorrência entre os sexos na busca do trabalho assalariado".

Com a reestruturação produtiva, engendrada na segunda metade do século XX, a informalidade, as formas de terceirização e as subcontratações se tornaram funcionais ao contexto da acumulação flexível (HARVEY, 1998), ou seja, da "empresa enxuta", mediante a crescente competitividade mundial, desregulamentação econômica, desemprego e precarização das relações de trabalho.

Ao mencionar a precarização como um dos eixos dessa discussão, Hirata e Préteceille(2002, p. 55), argumentam que, para conceituar a precarização social, há uma

(...) dupla institucionalização da instabilidade: precarização econômica (das estruturas produtivas e salariais) e precarização da proteção social (transformação das legislações relativas aos direitos do trabalho, das empresas e das situações externas ao trabalho).

Em linhas gerais, os autores argumentam que, na atualidade, as mulheres são as mais atingidas nesse processo de precarização, pois ainda são “(...) mais vulneráveis e menos legitimadas que os homens no espaço profissional" (HIRATA \& PRÉTECEILLE, 2002, p. 65-66).

No que tange às reivindicações dos/as trabalhadores/as, as atuais formas precárias de emprego e o crescente desemprego têm sido aspectos fulcrais para desmontar a capacidade organizativa da classe trabalhadora. Porém, mesmo diante de empecilhos e dificuldades, o fortalecimento de instâncias coletivas daqueles que vivem e sobrevivem do trabalho não é impossível e compete a eles “(...) inventar novas formas de ação coletiva” (HIRATA \& PRÉTECEILLE, 2002, p. 63).

\section{Apontamentos Finais}

Tendo em vista as mudanças em curso, o que pode ser constatado na indústria da confecção é que o processo de reestruturação produtiva, pela via da terceirização das atividades, ocorreu em ampla escala com o objetivo fundamental de redução dos custos da produção, sendo tal medida uma tendência generalizada no âmbito do mundo do trabalho, seja no plano local, regional, nacional ou internacional. Tal adoção não eliminou, nesse ramo de atividade, os caracteres tayloristas e, por isso, se verifica a permanência de uma rígida divisão do trabaIho marcada pela especialização e repetição das tarefas de baixa qualificação do trabalhador. 
Também é relevante pontuar que, historicamente, a indústria da confecção contribuiu de forma significativa para o ingresso das mulheres no mundo do trabalho. Porém, observa-se que ocorreu uma inserção marginalizada das muIheres na esfera produtiva face ao processo de reestruturação capitalista, pois a presença feminina nesse setor econômico foi majoritariamente em espaços periféricos, marcados pela precariedade do trabalho, sustentando a divisão sexual do trabalho. Às trabalhadoras, ficaram reservados postos de trabalho informais e subcontratados, e quando lhes foram assegurados os espaços fabris e formalizados, as tarefas reservadas ao público feminino foram caracterizadas pela desqualificação, repetição e menores salários, como é o caso da costura. Tal realidade apenas corrobora a atualidade do debate sobre a divisão sexual do trabalho, tendo em vista desvelar as múltiplas evidências das relações sociais expressas nas atividades produtivas e reprodutivas a partir do recorte de gênero.

Portanto, a divisão sexual do trabalho, compreendida como um construto que se modifica historicamente diante das sucessivas alterações da vida social, se estrutura e se organiza no mundo do trabalho na contemporaneidade de forma a conceber espaços diferenciados aos homens, ou seja, aqueles de maior qualificação, prestígio, status e melhores salários, enquanto que às mulheres são reservadas, predominantemente, atividades marcadas pela precarização, baixos salários, desprestígio e baixa qualificação, reforçando as assimetrias e desigualdades de gênero, em tempos de disputas e lutas pela garantia de projetos societários democráticos, igualitários e emancipatórios. Sendo assim, não se pode desconsiderar a divisão sexual do trabalho na compreensão da questão social e no entendimento das transformações societárias, tendo em vista que formas de discriminação e opressão, envolvendo as relações sociais entre homens e mulheres, ainda se fazem presentes e exigem estudos, pesquisas e problematizações com vistas a possíveis superações.

Abstract: The sexual division of labor, the march of productive restructuring, that triggered processes of outsourcing, informality and subcontracts, is an issue that still requires further studies and research with a view to decipher elements present a productive sphere that reinforces gender inequalities in the world of work. For this reason, this article aims to present some aspects of this complex phenomenon, inspiring reflections about a supposed end of the sexual division of labor, in the face of discourses disseminated that attest to the equality of men and women at the productive sphere. This conception is questionable considering that still maintain certain occupations in the world of work as bastions female par excellence, as is the case with the clothing industry. Keywords: Work, Gender, Insecurity, Clothing, Social Problem. 


\section{Anexo}

Tabela 1: Ocupação dos Candidatos 2010 e PNAD 2006

\begin{tabular}{|c|c|c|c|}
\hline Ocupações & $\begin{array}{c}\text { candidatos } \\
2010\end{array}$ & PNAD de 2006 & $\sim$ \\
\hline & \% válida & \% válida & \\
\hline Outros & 15,23 & & 0,00 \\
\hline Empresário & 8,59 & $\begin{array}{l}\text { Dirigentes de empresas - empregadores } \\
\text { com mais de } 5 \text { emprega }\end{array}$ & \\
\hline Advogado & 6,15 & & 0,55 \\
\hline Deputado & 5,66 & Legisladores & 0,03 \\
\hline Comerciante & 4,76 & $\begin{array}{c}\text { Representantes comerciais e técnicos de } \\
\text { vendas }\end{array}$ & 0,99 \\
\hline Vereador & 3,95 & & \\
\hline Servidor público estadual & 3,79 & & 1,90 \\
\hline Médico & 3,19 & & 0,27 \\
\hline Professor de Ensino Médio & 2,89 & & 3,11 \\
\hline Aposentado (exceto Servidor Público) & 2,46 & & \\
\hline Administrador & 2,23 & & 0,10 \\
\hline Policial Militar & 2,19 & & 3,20 \\
\hline Servidor público federal & 2,08 & & 0,80 \\
\hline Servidor público municipal & 1,86 & & 2,60 \\
\hline Professor de Ensino Superior & 1,58 & & 0,24 \\
\hline Engenheiro & 1,56 & Engenheiros e afins & 0,15 \\
\hline Estudante, bolsista, estagiário e assemelhados & 1,51 & & \\
\hline Professor de Ensino Fundamental & 1,20 & & 1,15 \\
\hline Dona de casa & 1,18 & & \\
\hline Jornalista e redator & 1,05 & Profissionais do jornalismo & 0,08 \\
\hline Contador & 0,91 & Contadores e auditores & 0,30 \\
\hline
\end{tabular}

Fontes: IBGE e TSE (elaboração do autor)

Tabela 2: Setor da ocupação - PNAD de 2006 e candidatos

\begin{tabular}{|c|c|c|c|c|c|c|c|}
\hline \multicolumn{2}{|c|}{ PNAD 2006: ocupacionalmente ativos } & \multicolumn{2}{c|}{ Eleições 2010 - todos os candidatos } & \multicolumn{2}{c|}{ Eleições de 2010 - eleitos } \\
\hline & Percent & Valid Percent & & Percent & Valid Percent & Percent & Valid Percent \\
\hline \hline Privado & 39,66 & 78,33 & setor privado & 24,89 & 44,27 & 15,96 & 18,64 \\
\hline Público & 10,97 & 21,67 & setor público & 12,65 & 22,51 & 47,05 & 54,93 \\
\hline Total & 50,64 & 100,00 & setor privado e público & 18,67 & 33,22 & 22,64 & 26,43 \\
\hline NR/NA & 49,36 & & Total & 56,22 & 100,00 & 85,65 & 100,00 \\
\hline Total & 100,00 & & NR & 43,78 & & 14,35 & \\
\hline & & & & 100,00 & & 100,00 & \\
\hline
\end{tabular}

Fontes: IBGE e TSE (elaboração do autor) 


\section{Referências}

ABREU, A. R. de P. O avesso da moda: trabalho a domicílio na indústria de confeç̧ão. São Paulo: Hucitec, 1986.

ABREU, A. R. de P. \& SORJ, B O trabalho invisível: estudos sobre trabalhadores a domicílio no Brasil. Rio de Janeiro: Rio Fundo, 1993.

ANTUNES, R. Adeus ao trabalho?: ensaios sobre as metamorfoses e a centralidade do mundo do trabalho. 12a ed. São Paulo: Cortez, 2007.

ARAÚJO, Â. M. C. \& AMORIM, E. R. A. "Redes de subcontratação e trabalho a domicílio na indústria de confecção: um estudo na região de Campinas". Cadernos Pagu, Campinas, n. 17/18, 2002, p. 267-310.

BRUSCHINI, C. "Gênero e trabalho no Brasil: novas conquistas ou persistência da discriminação? (Brasil, 1985/95)". In: M. I. B. da Rocha (Org.). Trabalho e gênero: mudanças, permanências e desafios. Campinas: ABEP: NEPO: UNICAMP, Ed. 34, 2000, p. 13-58.

BRUSCHINI, C. \& LOMBARDI, M. R. "Instruídas e trabalhadeiras: trabalho feminino no final do século XX". Cadernos Pagu, Campinas, n. 17/18, 2002, p. 157-196.

CACCIAMALI, M. C. "Globalização e processo de informalidade". Economia e Sociedade, Campinas, n. 14, 2000, p. 153-174.

CANDELA SOTO, P. "Género, trabajo y políticas de igualdad". Revista Sociología del trabajo, Universidad Complutense de Madrid, n. 64, 2008, p. 3-15.

CRUZ, T. "Ocupação no mundo do trabalho e o enfoque de gênero: qual o perfil do sujeito trabalhador que constrói a economia solidária no Brasil?" Sociedade e Cultura, Goiânia, v. 9, n. 2, 2006, p. 311-325.

DÍAZ VALERO, P. “Avanzar en igualdad: estudio sobre la organización del trabajo desde una perspectiva de género" Revista Sociología del trabajo, Universidad Complutense de Madrid, n. 64, 2008, p. 17-40.

GORZ, A. Adeus ao proletariado: para além do socialismo. Rio de Janeiro: Forense-Universitária, 1987.

HARVEY, D. Condição pós-moderna. 7ạ ed. São Paulo: Loyola, 1998.

HIRATA, H. "Globalização e divisão sexual do trabalho". Cadernos Pagu, Campinas, n. 17/18, 2002, p. 139-156. 
Nova divisão sexual do trabalho? Um olhar voltado para a empresa e a sociedade. São Paulo: Boitempo, 2002.

. "Reestruturação produtiva, trabalho e relações de gênero". Revista Latino-americana de Estudos do Trabalho, São Paulo, ano 4, n. 7, 1998, p.5 -27.

HIRATA, H. \& KERGOAT, D. "Novas configurações da divisão sexual do trabalho". Cadernos de Pesquisa, v. 37, n. 132, 2007, p. 595-609.

HIRATA, H. \& PRÉTECEILLE, E. "Trabalho, exclusão e precarização socioeconômica: o debate das Ciências Sociais na França". Caderno CRH, Salvador, n. 37, 2002, p. 47-80.

KERGOAT, D. "Divisão sexual do trabalho e relações sociais de sexo". In: H. Hirata (org.). Dicionário crítico do feminismo. São Paulo: Unesp, 2009.

. "A propósito de las relaciones sociales de sexo". In: H. Hirata e D. Kergoat. La división sexual del trabajo: permanencia y cambio. Asociación Trabajo y Sociedad, Argentina, 1997.

LAVINAS, L. "Evolução do desemprego feminino nas áreas metropolitanas". In: M. I. B. da Rocha (Org.). Trabalho e gênero: mudanças, permanências e desafios. Campinas: ABEP: NEPO: UNICAMP, Ed. 34, 2000.

LIMA, Â. M. de S. As faces da subcontratação do trabalho: um estudo com trabalhadoras e trabalhadores da confecção de roupas de Cianorte e região. $357 f$. Tese (Doutorado em Ciências Sociais) - Universidade Estadual de Campinas, Campinas, 2009.

LIMA, J. C. "Trabalho informal, autogestionário e gênero". Sociedade e Cultura, Goiânia, v. 9, n. 2, 2006, p. 303-310.

LIRA, I. C. D. "Informalidade: reflexões sobre o tema”. Serviço Social e Sociedade. São Paulo: Cortez, n. 69, 2002, p. 140-150.

MARUANI, M.; ROGERAT, C. \& TORNS, T. Las nuevas fronteras de la desigualdade: hombres y mujeres en el mercado de trabajo. Barcelona: Icaria Editorial, 2001.

NAVARRO, V. L. Trabalho e trabalhadores do calçado. São Paulo: Expressão Popular, 2006.

NEVES, M. de A. "Reestruturação produtiva, qualificação e relações de gênero". In: M. I. B. da Rocha (Org.). Trabalho e gênero: mudanças, permanências e desafios. Campinas: ABEP: NEPO:UNICAMP, Ed. 34, 2000, p. 171-185. 
"Trabalho e gênero: permanências e desafíos". Sociedade e Cultura, Goiânia, v. 9, n. 2, 2006, p. 257-265.

NEVES, M. de A. \& PEDROSA, C. M. "Gênero, flexibilidade e precarização: o trabalho a domicílio na indústria de confecções". Sociedade e Estado, Brasília, n. 1, v. 22, 2007, p.11-34.

NOGUEIRA, C. M. A feminização no mundo do trabalho: entre a emancipação e a precarização. Campinas: Autores Associados, 2004.

RAGO, M. Do cabaré ao lar: a utopia da cidade disciplinar (Brasil 1890-1930). 3ạ ed. Rio de Janeiro: Paz e Terra, 1997.

RIVAS, A. M. \& RODRÍGUEZ, M. J. Mujeres y hombres en conflicto: trabajo, familia y desigualdades de género. Madrid: Ediciones HOAC, 2008.

TORNS, T. "Las asalariadas: un mercado con género" In: C. Prieto \& F. Miguélez (dir). Las relaciones de empleo en España. Madrid: Siglo XXI de España Editores, 1999, p. 151-166.

TORNS, T.; BORRÀS, V. \& ROMERO, A. "El acoso sexual en el mundo laboral: un indicador patriarcal". Revista Sociología del Trabajo, Universidad Complutense de Madrid, n. 36, 1999, p. 57-78. 